Document downloaded from:

http://hdl.handle.net/10251/55525

This paper must be cited as:

Schmid, SR.; Liu, J.; Sellés Cantó, MȦ.; Pasang, T. (2013). Advanced interface models for metal forming simulations. Computational Materials Science. 79:763-771. doi:10.1016/j.commatsci.2013.07.025.

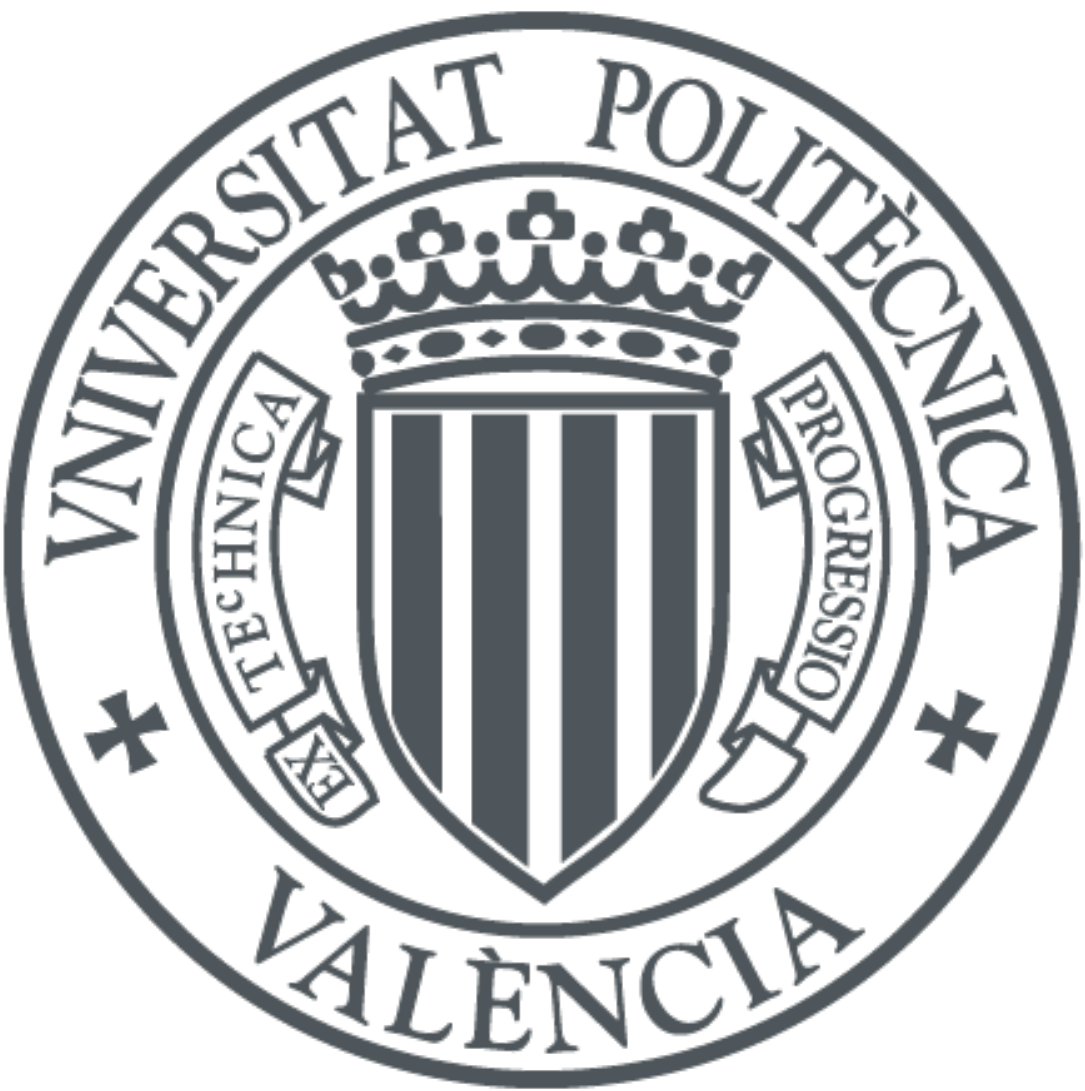

The final publication is available at

http://dx.doi.org/10.1016/j.commatsci.2013.07.025

Copyright Elsevier

Additional Information 


\title{
Advanced Interface Models for Metal Forming Simulations
}

\author{
S.R. Schmid ${ }^{\mathrm{a}}$, J. Liu ${ }^{\mathrm{b}}$, M.A. Sellés ${ }^{\mathrm{c}, *}$, T. Pasang ${ }^{\mathrm{d}}$ \\ ${ }^{a}$ Department of Aerospace and Mechanical Engineering, University of Notre Dame, Notre Dame, IN \\ 46556, USA \\ ${ }^{b}$ Department of Aerospace and Mechanical Engineering, University of Notre Dame, currently \\ Schlumberger Corp, Houston TX, USA. \\ ${ }^{c}$ Department of Materials and Mechanical Engineering, Universitat Politècnica de València, Alcoy, \\ Spain \\ ${ }^{d}$ Department of Mechanical Engineering, Auckland Technical University, Auckland, New Zealand
}

\begin{abstract}
Friction and heat transfer in metal forming simulations are usually restricted by software to be interface constants, a situation not reflected by the mechanics of real manufacturing processes. A better simulation approach is to use a micromechanics based method to estimate friction and heat transfer as evolutionary phenomenon. This paper presents a friction and heat transfer module for hot forging simulations. The friction model is based on a lubricant film thickness calculation using the Reynolds equation, and a calculation of the fractional contact area based on asperity flattening and roughening. Friction is then portioned between asperity and lubricant contacts. Heat transfer coefficients are calculated using a new model for heat conduction through asperity contact patches and lubricant that takes into account the restriction to heat flow at the contacts. The program is implemented as a user routine in a popular commercially available finite element code, DEFORM 2D.
\end{abstract}

Keywords: Friction, Heat transfer, Simulation, Sheet metal forming, FE Modeling

\section{Introduction}

Simulation of forming processes has become a standard step in the design of tooling. This is not too surprising given the large cost, which can exceed $\$ 2$ million for large or complicated forging dies for example. A process designer will evaluate a prospective

\footnotetext{
* Corresponding author

$U R L$ : maselles@dimm.upv.es (M.A. Sellés)

Preprint submitted to Computational Materials Science
}

July 5, 2013 
tooling design and conduct simulations to ensure that the material will flow to the desired shape without developing defects such as folds, cracks, or underfills [1]. Advanced models are available to predict the evolution of the material microstructure as well as the fracture of the workpiece, and very advanced material models can be used, including arbitrary stress-strain curves with allowance for strain rate and thermal effects. This paper will emphasize applications in forging, although the same approach could easily be used for any other bulk deformation process such as rolling (and all of its variants), extrusion, drawing or swaging. Despite all of the effort invested into the development of computational tools, very little attention has been directed towards improving the approaches used to model friction and heat transfer in metal forming processes. There have been several studies that developed advanced models for the coefficient of heat transfer at the part-tool interface, such as [2] and [3], and many that have focused on the calculation of the coefficient of friction in metal forming process, as in [4] and [5]. However, there have been few studies that accurately modeled friction and heat transfer simultaneously. This is especially surprising since it is well known that friction strongly affects deformation geometry (see, for example, Jackson [6]), and the temperature history affects the microstructure of the metal. The influence of tool design on friction in various metal forming operations has been extensively studied by Kirkhorn et al. [7], and their work has shown tool design is an imperative factor in the friction produced in metal forming processes and can affect production time, cost, and quality of produced parts. Tooling designers overcome these difficulties by running a number of simulations under different friction conditions and heat transfer coefficients until a design is achieved that appears to work satisfactorily under all conditions. The process is time consuming, computationally inefficient, and does not ensure efficient designs. Friction and heat conduction are evolutionary phenomena in metal forging. Simulations that freeze friction coefficients or heat transfer coefficients at constant value are inherently flawed, as seen in Kucharski et al. [8] study involving surface roughness in metal forming. While a somewhat flawed analysis can still give qualitative feedback, as in [8], and some assurance that a design is reasonable, its value in predicting the influence of process variables is limited. The main problem with modeling friction and heat transfer in metal forming is that both are poorly understood by code developers. Commonly, Coulomb models (with a constant 
friction coefficient) or Tresca models (with a constant friction factor or friction stress) are implemented in commercial codes, but these models do not account for the influence of parameters such as pressure, punch speed, or deformation of the material [9]. Friction will change as the real area of contact changes, as explored by Hol et al. [9] and Buchner et al. [10], and based on their studies, how friction is accounted for in computer simulations can greatly alter the validity of theoretical results. The same is true for constant heat transfer coefficients that are implemented in commercial codes. If advanced heat transfer models are properly implemented, such as in [2], [3], and [11], then there is a stronger correlation between experimental and theoretical results, thus making simulations more reliable for designers and manufacturers. Although Coulomb and Tresca models are suitable for most machine element contacts, but not for metal forming where surfaces stretch, film thicknesses evolve during the process, temperature gradients are severe and real fractional contact areas are very high. This paper summarizes the framework for a new friction and heat transfer model implemented in the DEFORM 2D commercial finite element program. More details of the mathematical modeling can be found in Schmid et al. [12], and Liu et al. [13]. Discussion is centered around simple upsetting and ring compression tests, although the importance of accurate friction and heat transfer models are even more important for more complicated geometries.

\section{Friction Model}

Schmid and Wilson [14], Schmid, Sellés and Pasang [15] and Lin and Chen [16] discuss the general situation of tribology in metal forming. Metal forming tribology is very different from conventional tribology encountered in machine elements such as bearings, cams and brakes. Although some authors have focused the research on dry contacts in metal forming (see, for example, Ramezani and Ripin [17], this paper shows that an effective lubricant film can develop in some parts of a die but not others, and it may persist during an operation under some conditions and break down under others. In [7], friction involved with the use of lubricants is studied, but with a focus on cold forming processes, rather than the hot forming processes that are the focus of this study. The effect various sheet metal coatings have on the friction involved in hot stamping have been studied, as in [18], but this work will focus mainly on hot forging processes. 


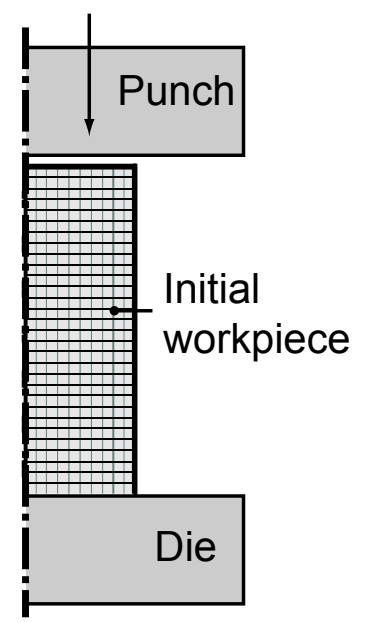

(a)

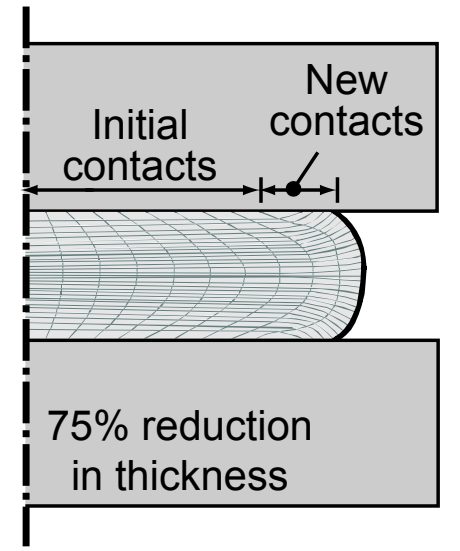

(b)

Figure 1: Schematic illustration of upsetting, demonstrating the poor efficiency of the finite element discretization for use in calculating tribology variables.

The lubricant film thickness developed and evolved during forging depends on lubricant properties, strain history, and process parameters such as speed and temperature. The process geometry plays a large role as well. Consider the axisymmetric compression, or upsetting, situation depicted in Fig. 1. The initial contact occurs over a finite contact area or patch, and as the cylinder is reduced in height, the initial contact patch expands while the original sidewall edges of the cylinder come into contact. This means that there are really two classes of problems for calculating film thickness in forging. The first involves calculating a film thickness for a location where film thickness existed in the previous timestep, and the second involves calculating a film for new or expanding contacts between tool and workpiece.

For initial contact patches, the Reynolds equation could conceivably be used to obtain the film thickness. However, this approach is extremely burdensome from a computational standpoint. Fortunately, the Reynolds equation has been solved for special cases that are useful in determining film thickness. A complete discussion of the film thickness equations used in the tribology module summarized in this paper is contained in Wilson [19], and only a brief summary is contained here. For an isoviscous lubricant, as can occur with some cold forming lubricants or some glasses in hot forging, the central film 
thickness for a flat patch of width $x$ and large thickness, first coming into contact is:

$$
h_{o}=\left(\frac{3 \eta_{o} V x^{2}}{\sigma}\right)^{1 / 3}
$$

where $h_{o}$ is the lubricant film thickness, $\eta_{o}$ is the viscosity, $V$ is the approach velocity and $\sigma$ is the material flow strength. For the isothermal case with a piezoviscous (pressuredependant viscosity) lubricant, as classically occurs with paraffinic oils in cold forging,

$$
h_{o}=\left(\frac{3 \eta_{o} \alpha V x^{2}}{1-e^{-\alpha \sigma}}\right)^{1 / 3}
$$

where $\alpha$ is the pressure exponent of viscosity. As the workpiece flattens, the macroscopic or apparent contact area between the workpiece and tooling grows, as shown in Figure 1b. The film thickness that is entrained at the edge of contact is given for an isoviscous case by

$$
h_{o}=\frac{3 \eta_{o}\left(u_{1}+u_{2}\right)}{\sigma \tan \theta}
$$

where $u_{1}$ is the rate of expansion of the contact patch, $u_{2}$ is the horizontal velocity of the die surface (which is often zero), and $\theta$ is the contact angle between the workpiece and tooling surface. For the isothermal piezoviscous case, the film thickness is

$$
h_{o}=\frac{3 \eta_{o} \alpha\left(u_{1}+u_{2}\right)}{\tan \theta\left(1-e^{-\alpha \sigma}\right)}
$$

For a perfectly plastic lubricant of shear strength $\tau_{l}$, the central film thickness is given by

$$
h_{o}=\frac{2 \tau_{l} x}{\phi \sigma}
$$

where $\phi$ is a redundant work factor. Equation (5) only holds if the result is smaller than the applied thickness; otherwise the film thickness can be equated to the applied film thickness. The film thickness that evolves inside a contact patch can be calculated from the unsteady Reynolds equation for the case where film thickness is evolving at a point of interest. Wilson and Marsault [20] provide a formulation of the Reynolds equation suitable for the conditions found in metal forming. This is adopted in this paper, with simplifications associated with forging applications. 


\section{Friction Calculation}

A fundamental difference between metal forming tribology and other tribology fields is the dynamic behavior of the surface topography. At the very least, it should be recognized that the surface roughness of the workpiece is not constant, that it can increase or decrease depending on a number of conditions. The model for surface roughness evolution is discussed in detail in Schmid et al. [12]. Surface roughness is calculated based on the lubricant film. If the lubricant film is very thin, then the tooling surface finish is impressed onto the workpiece. A thicker film reduces the roughness in proportion to the film thickness, unless this prediction would exceed the natural roughness of the material, which is used in such conditions.

Wilson, Huang and Tsu [21] suggest an expression for the friction stress $\tau_{f}$

$$
\tau_{f}=c k A+\theta_{t} k H A+\tau_{l}(1-A)=m_{m} k A+m_{l} k(1-A)
$$

where $c$ is an adhesion coefficient, $A$ is the fractional contact area, $k$ is the material shear strength, $\theta_{t}$ is a plowing coefficient (and is proportional to the surface slope and therefore related to the roughness), and $H$ is the surface hardness. $m_{m}$ is the combined effect of adhesion and plowing. The real area of contact is needed in order to obtain estimates of friction in the interface. If the film thickness is greater than three times the composite surface roughness, then fluid film lubrication occurs and the contact area is essentially zero. In this case, the friction will arise from the lubricant alone. If the film thickness is less than three times the surface roughness, the real area of contact for a Gaussian surface can be taken from the model of Christensen [22]:

$$
A=\frac{35}{32}\left(\frac{16}{32}-z+z^{3}-\frac{3}{5} z^{7}+\frac{1}{7} z^{7}\right)
$$

where $A$ is the contact ratio and $z$ is a surface parameter given by

$$
z=\frac{\bar{h}}{3 S_{q}}
$$

where $\bar{h}$ is the nominal surface separation, that is, the distance between mean planes of undeformed surfaces, and $S_{q}$ is the composite surface roughness. This area of contact, 
which depends on the current surface roughness and lubricant film, is then substituted into Eq. (6) to obtain an estimate of friction in metal forming.

\section{Heat Transfer Calculation}

The previous section presented a model for friction in isothermal forging operations in which the tooling is maintained at a temperature close to that of the workpiece. However, in most forging operations the tooling is significantly cooler than the workpiece. This has important implications for simulations, namely that heat transfer at the workpiece/tooling interface serves to chill layers of the workpiece near the tooling. Since strength and stiffness increase with decreasing temperature, chilling can restrict deformation just as much as friction does [23].

Modern finite element codes have a built-in capability for calculating the heat generated in plastic deformation and frictional sliding at workpiece tooling interfaces. In addition, they have heat convection and conduction options readily available for workpiece surfaces. However, a constant heat transfer coefficient is commonly used to simulate heat transfer across tooling/workpiece interfaces. This does not accurately reflect the heat transfer process in hot stamping simulations, as shown in [3],[11], and [24], where advanced heat transfer models implemented in computer simulations strongly correlate to experimental results.

Just as friction should be an evolutionary variable, it should be recognized that heat transfer coefficients change during forging. Heat transfer across the tooling/workpiece interface is a complex combination of conduction across asperity contacts and heat transfer across the lubricant film. Based on results in [2], contact pressure and physical characteristics of the material also affect the heat transfer at the part-tool interface. Usually the lubricant conducts heat with far less efficiency than metal on metal contacts and acts as a thermal barrier.

In their model, Wilson et al. [12] assumed all the asperity contacts are circular with radius a spaced a distance $2 L$ apart. Heat flow away from the asperity contact is assumed to be radial over a conical region. At a depth $d$ these regions merge and thereafter heat flow is uniform and normal to the surface. They partitioned the heat flow between the asperities and lubricant, so that the total interface film conductivity $U_{1}$ is the sum of the 
film conductivities associated with heat flow through the asperity contacts and through the lubricant film, or

$$
U_{1}=U_{c}+U_{f}
$$

They developed the following equation for film conductivity $U_{c}$ for conduction through the asperity contacts:

$$
U_{c}=\frac{1}{d} \frac{\sqrt{A}}{(1-\sqrt{A})} \frac{k_{t} k_{w}}{\left(k_{t}+k_{w}\right)}
$$

where $d$ is the depth of the thermal layer, that is, the depth beyond which heat flow is uniform, and $k_{t}$ and $k_{w}$ are the thermal conductivities of the tooling and workpiece, respectively. $d$ can be approximated as the spacing between asperity peaks for forging applications. Heat flow also occurs through the lubricant film. Liu et al. [13] derive an expression for film conductivity as

$$
U_{f}=\frac{(1-A)}{h_{f}} \frac{2 k_{f} k_{t} k_{w}}{\left(2 k_{t} k_{w}-k_{w} k_{f}-k_{f} k_{t}\right)}
$$

where $k_{f}$ is the thermal conductivity of the lubricant and $h_{f}$ is the average film thickness in the area of interest, defined as the ratio of lubricant volume to apparent contact area. Note that by definition, $\bar{h}$ in Eq. (8) can become zero or even negative for flattening surfaces, whereas $h_{f}$ will always remain positive. For Gaussian surfaces, $h_{f}$ and $\bar{h}$ are related by

$$
h_{f}=\frac{3\left(35+z\left(128+z\left(140+z^{2}\left(-71+z^{2}\left(28-5 z^{2}\right)\right)\right)\right)\right)}{256}
$$

where $z$ has been defined in Eq. (8). The average film thickness $\bar{h}$ can be estimated based on the rheology of the lubricant using Eqs. (1) through (5), or else can be implemented as a local calculation as a user routine in modern finite element codes. The fractional contact area is obtained from Eq. (7).

Figure 2 shows the results when this model is compared to experiments conducted by Nshama and Jeswiet [25]. Nshama and Jeswiet reported that the average film heat transfer coefficients for unlubricated ring compression tests of aluminum was $100 \mathrm{~kW} / \mathrm{m}^{2} \mathrm{~K}$ and $50 \mathrm{~kW} / \mathrm{m}^{2} \mathrm{~K}$ for cold and hot forging, respectively. However, the "hot forging" performed 


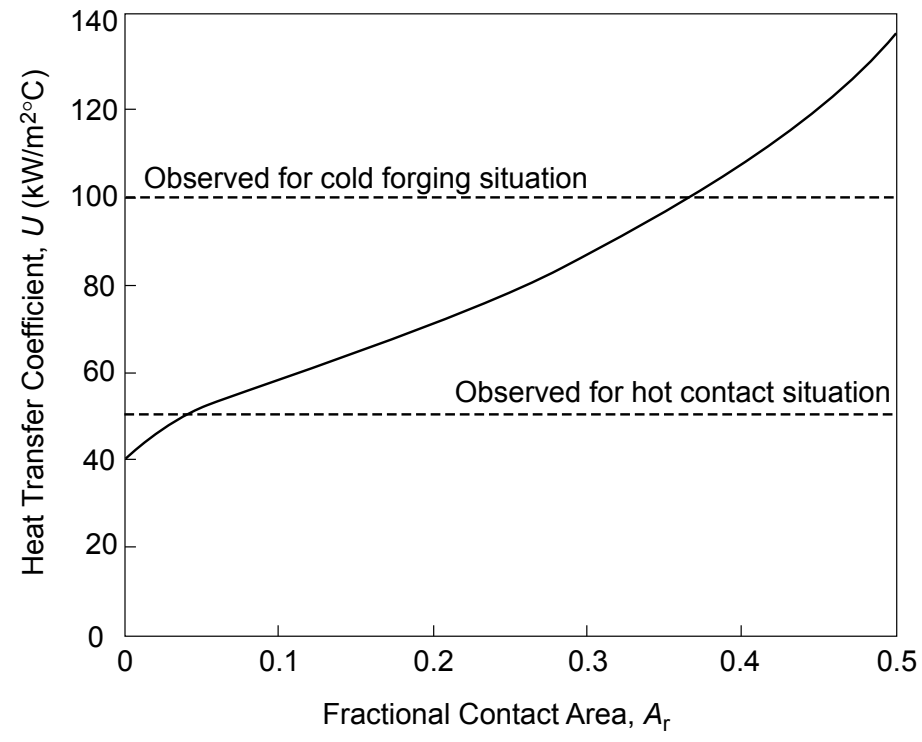

Figure 2: Heat transfer coefficient as a function of fractional contact area, with comparison to the experimental observations of Nshama and Jeswiet [25]

by Nshama and Jeswiet was not actually a forging operation, as the dies were allowed to touch the workpiece with sufficient pressure to provide good thermal contacts without undergoing plastic deformation. Using the thermal properties of air for the lubricant with a film thickness equal to the workpiece roughness yields the results in Fig. 2. It is difficult to directly apply the experiments of Nshama and Jeswiet, because the fractional contact area in their experiments was not measured and insufficient information was given to obtain an estimate. However, the heat transfer coefficients correspond to reasonable values of fractional contact area.

\section{Implementation}

The average film thickness and the fractional contact area are variables that are known to evolve during a forging operation. In implementing the models to the finite element program, a number of complications needed to be taken into account, including:

- A separate discretization is needed, since the finite element discretization is not optimal for the tribology module; unless the mesh is excessively fine, there will be 
insufficient nodes at the locations where the friction and heat transfer coefficients are changing rapidly.

- Implementations of finite element approaches specialized for metal forming will periodically remesh to produce accurate plasticity solutions and good convergence. Remeshing usually produces a new mesh that exacerbates the problems of element availability.

- The element connectivity will not be convenient for the friction and heat transfer module implementation.

The main evolutionary variables that affect the heat transfer routine are film thickness and real area of contact, and these are both stored as user variables at tribology nodes. Therefore, a call to the heat transfer subroutine merely requires a mapping of the nodes on the element side of interest to the tribology nodes and an interpolation of already calculated film thickness and fractional contact areas. The heat transfer coefficient is then obtained from Eqs. (9)-(11). It should be noted that since the heat transfer module depends on the friction routine, it cannot be run independently. However, the friction model can be run without the heat transfer model for isothermal conditions.

\section{Results}

Figure 3a depicts the strain evolution for ring compression test simulations using titanium alloy Ti-4V-6Al at a workpiece temperature of $980^{\circ} \mathrm{C}$ and tooling temperature of $200^{\circ} \mathrm{C}$, with a constant friction factor $m$ of 0.2 and constant heat transfer coefficient $U$ of $5 \mathrm{~kW} / \mathrm{m}^{2} \mathrm{~K}$. Figure $4 \mathrm{~b}$ shows the strain evolution for a simulation where the heat transfer coefficient $U$ has been changed to $20 \mathrm{~kW} / \mathrm{m}^{2} \mathrm{~K}$. The noticeable impact on the strain distribution clearly demonstrates the idea that heat transfer has at least as much effect on metal deformation as friction. Chilling of the workpiece due to better heat transfer leads to increased resistance to deformation.

The plastic strain obtained using the tribology and heat transfer models is shown in Fig. 4. The results in Figs. 3 and 4 are similar because the friction factor in Fig. 3 was selected to reproduce the experiments of Kannan, et al. [26]. Tribology and heat 


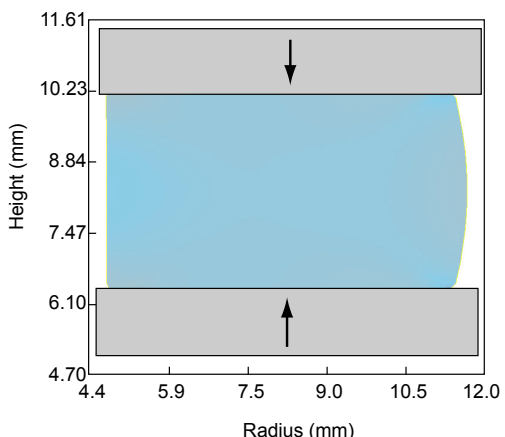

(a)

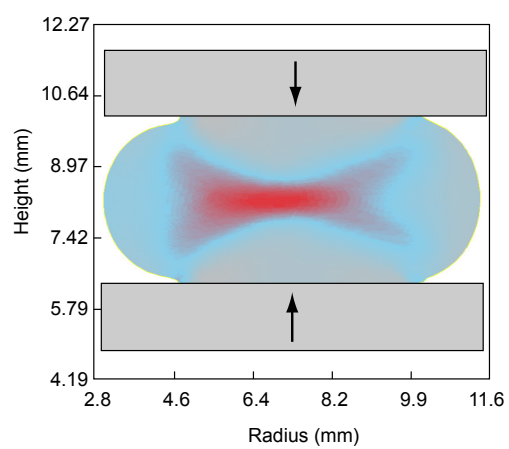

(c)

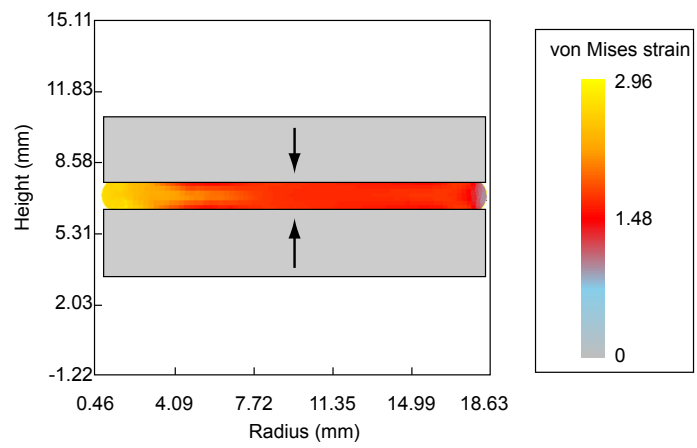

(b)

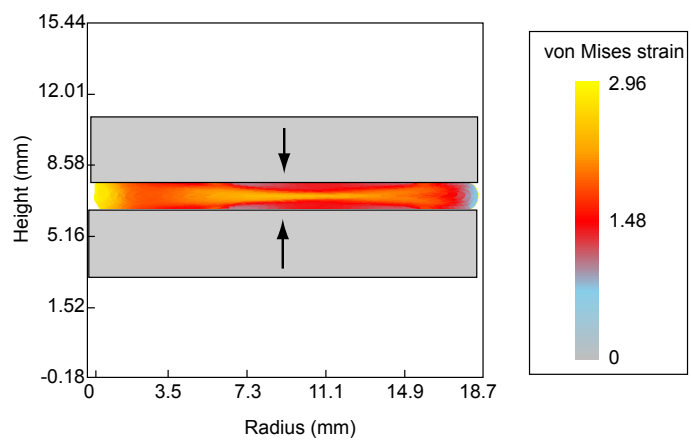

(d)

Figure 3: Ring compression test simulations with constant friction at two heat transfer coefficients. (a) $U=5 \mathrm{~kW} / \mathrm{m}^{2}{ }^{\circ} \mathrm{C}$ and $m=0.2$ at 20 percent reduction in thickness; (b) $U=5 \mathrm{~kW} / \mathrm{m}^{2}{ }^{\circ} \mathrm{C}$ and $m=0.2$ at 80 percent reduction in thickness; (c) $U=20 \mathrm{~kW} / \mathrm{m}^{2}{ }^{\circ} \mathrm{C}$ and $m=0.2$ at 20 percent reduction in thickness; (d) $U=20 \mathrm{~kW} / \mathrm{m}^{2}{ }^{\circ} \mathrm{C}$ and $m=0.2$ at 80 percent reduction in thickness. 


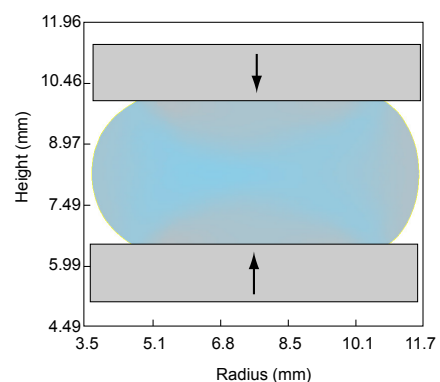

(a)

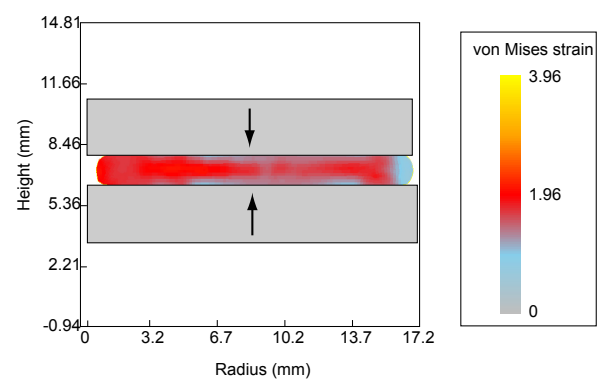

(b)

Figure 4: von Mises strain using the tribology and heat transfer models for a ring compression test. (a) $20 \%$ reduction in thickness; (b) $80 \%$ reduction in thickness.

transfer model inputs such as the friction factor for direct asperity-to-asperity contacts and lubricant properties were defined from these experiments.

Note the difference in the temperature evolution for the ring compression tests shown in Fig. 5. With the constant heat transfer coefficient, the tooling extracts heat more rapidly towards the center of the ring, since this location has encountered the most prolonged contact. In Fig. 5b, the tooling heats more quickly at the outside of the ring compression test specimen. This can be explained by Fig. 6 , which shows the distribution of film thickness and heat transfer coefficient across the tooling/specimen interface. As can be seen, the central portion develops a thick lubricant film. Since the lubricant is an effective thermal insulator, heat transfer is greatly slowed in this region. As the ring rolls into contact with the tooling, a thin lubricant film develops and a high heat transfer coefficient is predicted because of the large frictional contact areas and conduction that occurs directly across asperities. Temperatures increase rapidly in the location of the thin lubricant film thickness.

\section{Experimental data and model verification}

A number of real tests and simulations were performed to evaluate the performance and robustness of the tribology models. For the purposes of this research, it should be noted that "hot forging" refers to situations where a temperature difference exists between the workpiece and tooling. The material used for this paper are steel tooling and Ti-6Al-4V as the workpiece, with a preheat of $983 \circ \mathrm{C}$ and a tooling temperature of 


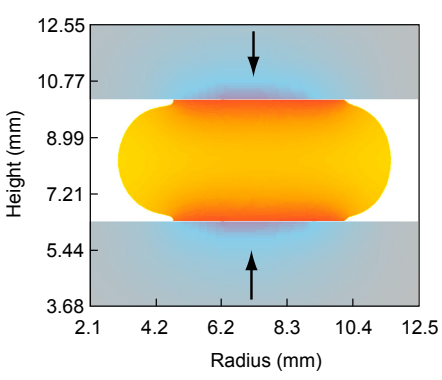

(a)

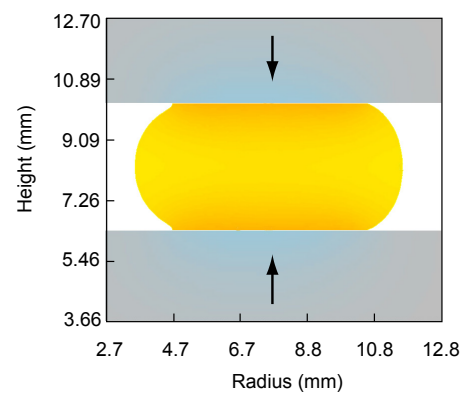

(c)
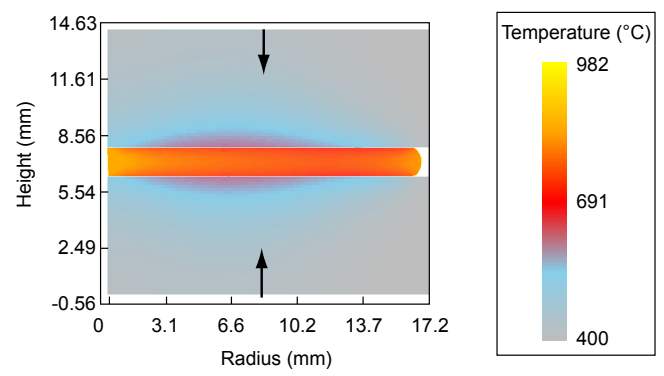

(b)

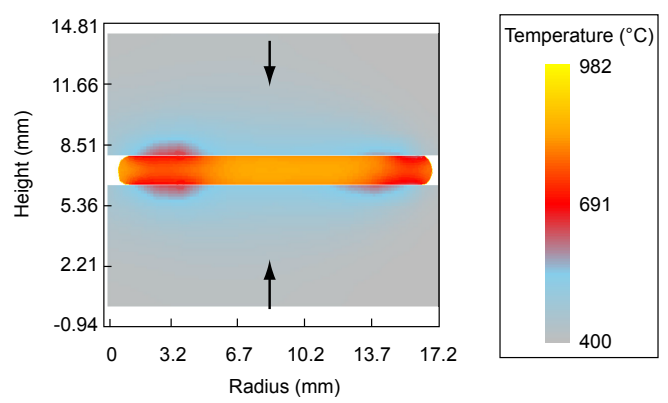

(d)

Figure 5: Temperature profiles in simulations of ring compression test. (a) Constant heat transfer coefficient of $U=20 \mathrm{~kW} / \mathrm{m}^{2}{ }^{\circ} \mathrm{C}$ and $m=0.2$ at $20 \%$ reduction in thickness; (b) constant heat transfer coefficient of $U=20 \mathrm{~kW} / \mathrm{m}^{2}{ }^{\circ} \mathrm{C}$ and $m=0.2$ at $80 \%$ reduction in thickness; (c) tribology and heat transfer model at $20 \%$ reduction in thickness; (d) tribology and heat transfer model at $80 \%$ reduction in thickness.

$204 \circ \mathrm{C}$. The lubricant used has been a glass, which is taken as a liquid whose viscosity depends on temperature only. Based on measurements conducted by Kannan et al. [26], the viscosity of the glass is taken as 0.675 Pas, and the thermal conductivity for it is 1.4 $\mathrm{W} / \mathrm{m} 2 \mathrm{~K}[27]$.

Hot forging is widely used because many materials are difficult to form at room temperature, but have acceptable forgeability at elevated temperatures, and do not need the complexity of isothermal forging.

\subsection{Ring compression test (RCT) with constant friction and heat transfer coefficient}

The geometry for the following RCTs is shown in Fig.7. Figure 8 depicts the strain evolution for ring compression test simulations using titanium alloy Ti-6Al-4V at a workpiece temperature of $983 \circ \mathrm{C}$ and tooling temperature of $204 \circ \mathrm{C}$, with a constant friction factor of $\mathrm{m}=0.2$ and constant heat transfer coefficient of $\mathrm{U}=1 \mathrm{~kW} / \mathrm{m} 2 \mathrm{~K}$. Figure 9 


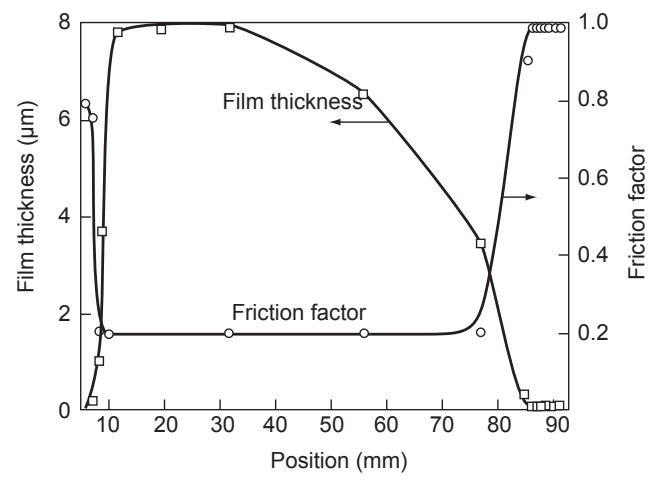

Figure 6: Film thickness and heat transfer coefficient evolution for a ring compression test at $80 \%$ reduction in thickness.

shows the strain evolution for a similar simulation where the heat transfer coefficient $U$ has been modified to $20 \mathrm{~kW} / \mathrm{m} 2 \mathrm{~K}$.

Because of the temperature difference between the workpiece and tooling, the heat transfer is clearly important for hot forging and can significantly affect deformation, as shown in Figures 8 and 9. Schey [23] claims that the cooling and workpiece hardening associated with heat transfer between the workpiece and the tooling can be as important as friction. The results shown in Figs 8 and 9 suggest that heat transfer is even a more important factor than friction in this case. It should be noted that an $80 \%$ reduction in height was not achieved because the internal diameter already decreased to 0 at $76 \%$ reduction.

\subsection{Ring compression test with friction and heat transfer models}

Figure 10 shows the strain results for ring compression test simulations using titanium alloy Ti-6Al-4V at a workpiece temperature of $983 \circ \mathrm{C}$ and tooling temperature of $204 \circ \mathrm{C}$. Figure 10 shows the classic barreled profile where a surface layer has been cooled due to heat transfer to the tooling, and the strains are similar to the situation in Figure 9.

Figure 11 shows the heat transfer coefficient evolution for this simulation. The heat transfer coefficient changed a great deal, from an initial value of 5 to a peak of 100 $\mathrm{kW} / \mathrm{m}^{2} \mathrm{~K}$. It has the same trend of evolution as friction, which makes sense since they are both related to the lubricant film thickness. It can be noted that the heat transfer coefficient is more sensitive to film thickness than friction coefficient. 


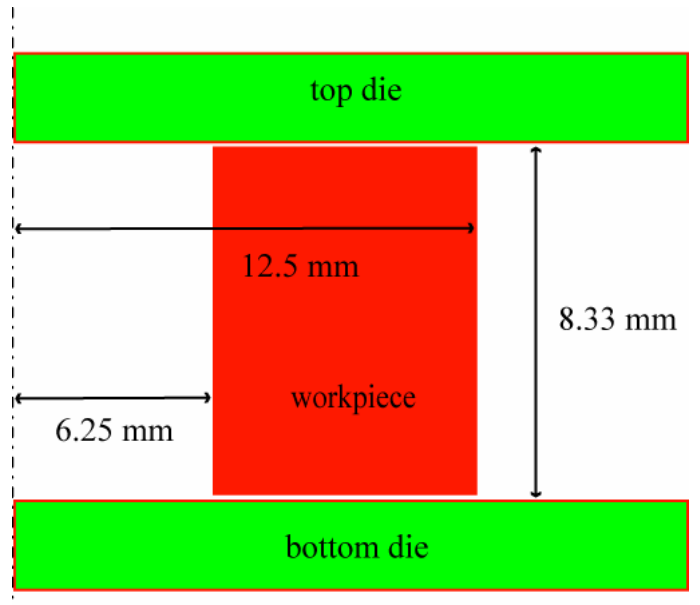

Figure 7: Ring compression test of 6 (outer diameter): 3 (inner diameter): 2 (height) proportion.

Shown in Figure 12, tribology model was compared with the constant value approach. The same trend as in the friction model, which crosses constant friction factor curves from low to high values, is observed for heat transfer model. Clearly, heat transfer is essential to be modeled accurately in hot forging, possibly even more important than friction.

\section{Conclusions}

A module for friction and heat transfer in forging operations has been described. The model is implemented as a user routine in DEFORM2D, a popular commercial finite element program for metal forming simulation. The model gives qualitatively and quantitatively promising results for a number of tooling/workpiece and lubricant material combinations. It allows for the friction factor and heat transfer coefficient to evolve according to process parameters such as roughness and film thickness, so that a more sophisticated treatment of heat transfer in forging simulations can take place. Both models of friction and heat transfer compare well qualitatively and quantitatively to published measurements. Application of these two models would allow friction and heat transfer to naturally evolve, resulting in more realistic metal forming simulations. 


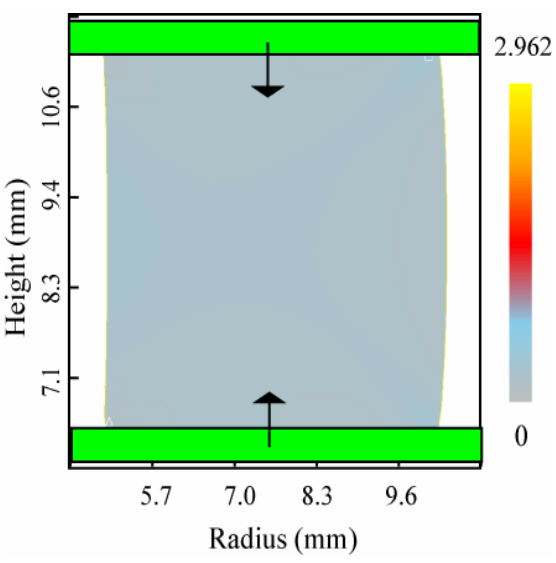

(a)

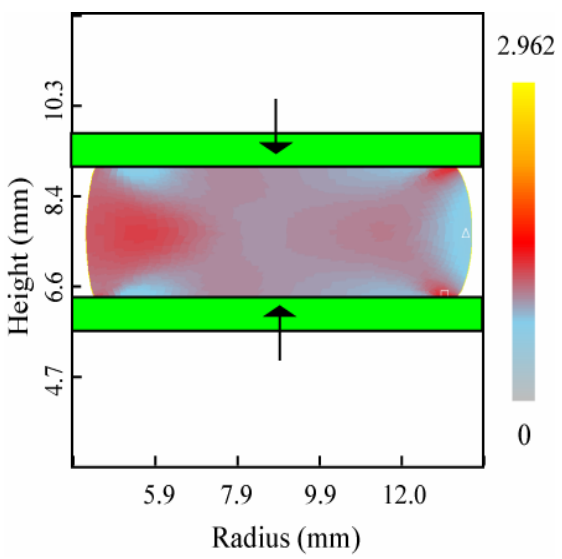

(c)

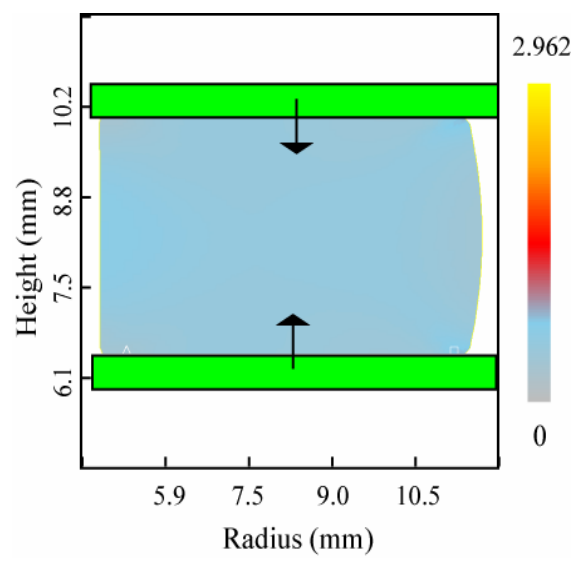

(b)

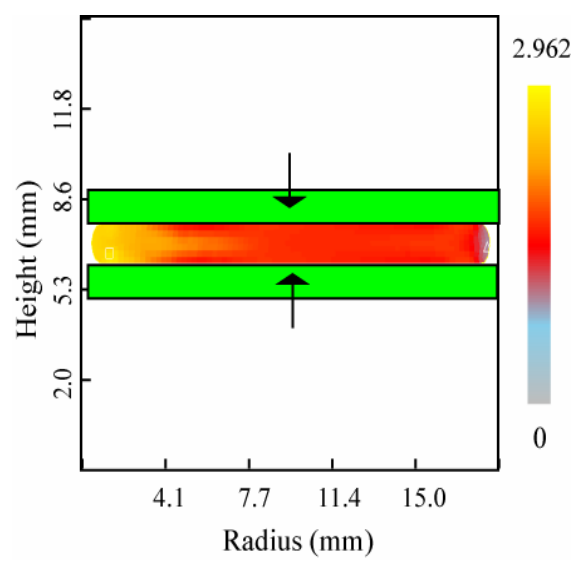

(d)

Figure 8: Strain evolution for hot forging of Ti-6Al-4V in a ring compression test geometry, using constant $m=0.2$ and $\mathrm{U}=1 \mathrm{~kW} / \mathrm{m}^{2} \mathrm{~K}$. (a) $20 \%$ reduction in thickness; (b) $40 \%$ reduction in thickness; (c) $60 \%$ reduction in thickness; (d) $76 \%$ reduction in thickness. 


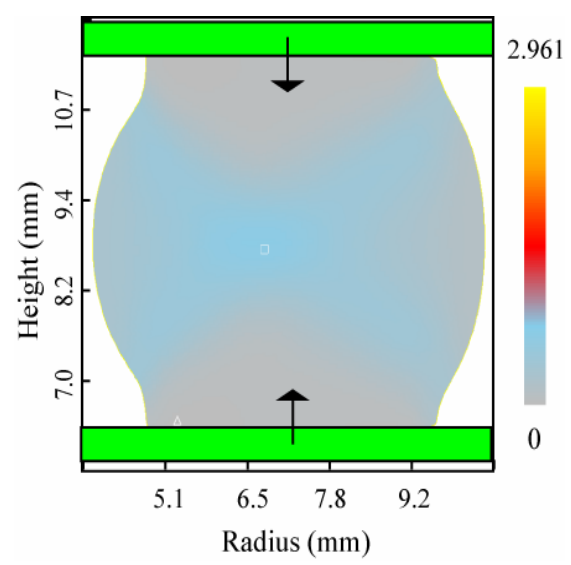

(a)

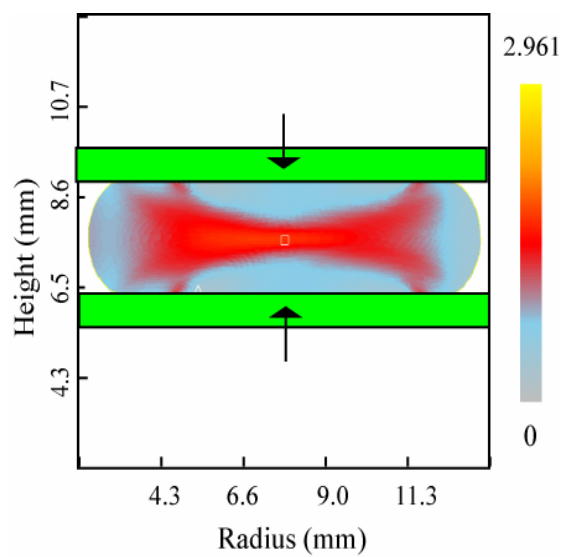

(c)

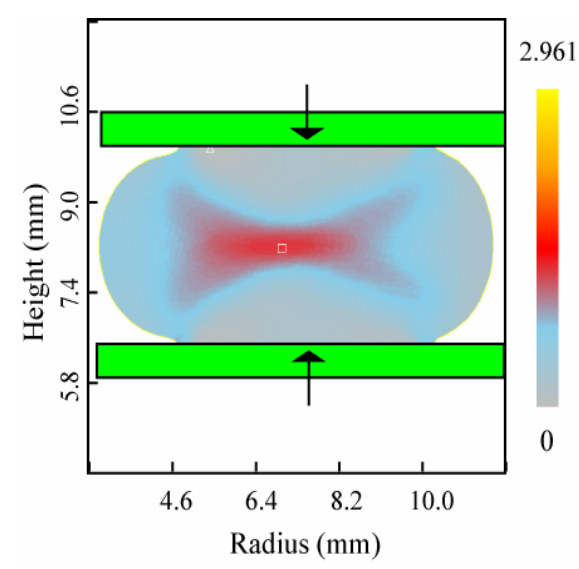

(b)

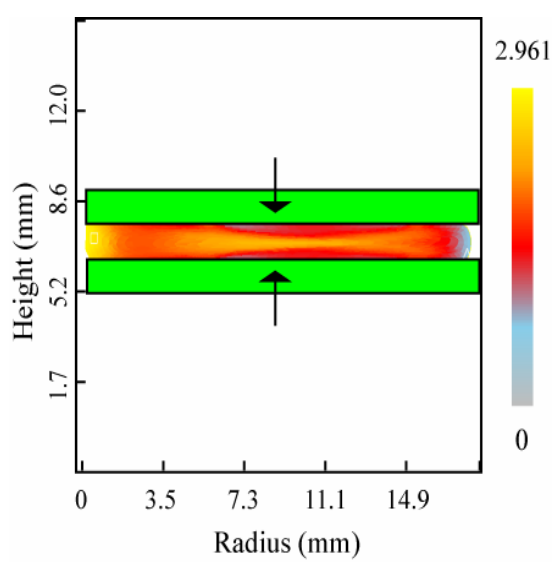

(d)

Figure 9: Strain evolution for hot forging of Ti-6Al-4V in a ring compression test geometry, using $m=0.2$ and $\mathrm{U}=20 \mathrm{~kW} / \mathrm{m}^{2} \mathrm{~K}$. (a) $20 \%$ reduction in thickness; (b) $40 \%$ reduction in thickness; (c) $60 \%$ reduction in thickness; (d) $76 \%$ reduction in thickness. 


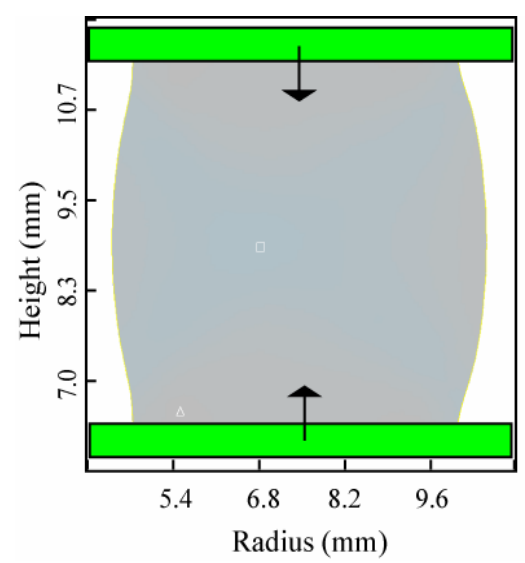

(a)

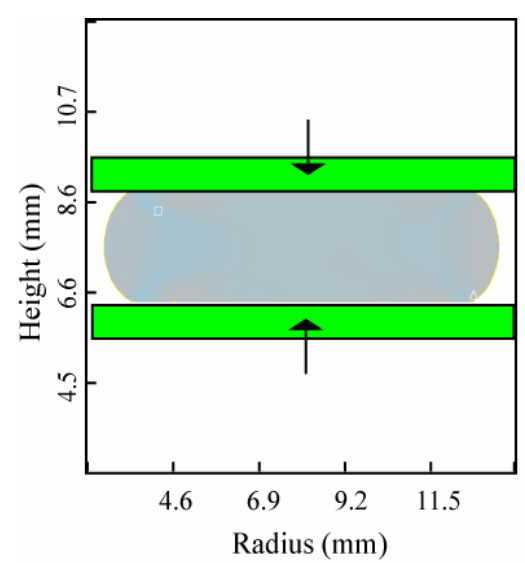

(c)

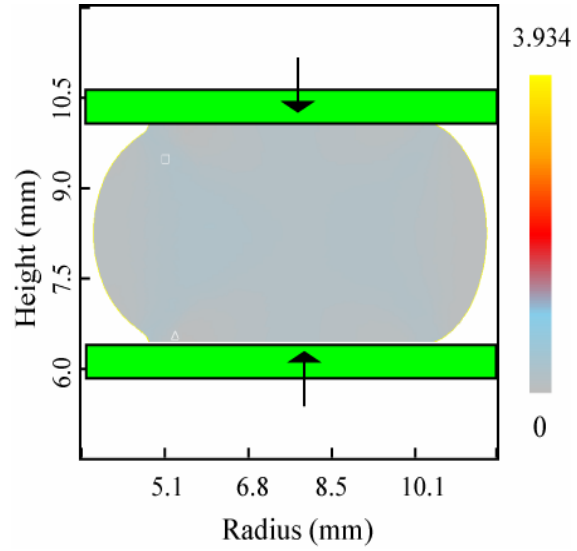

(b)

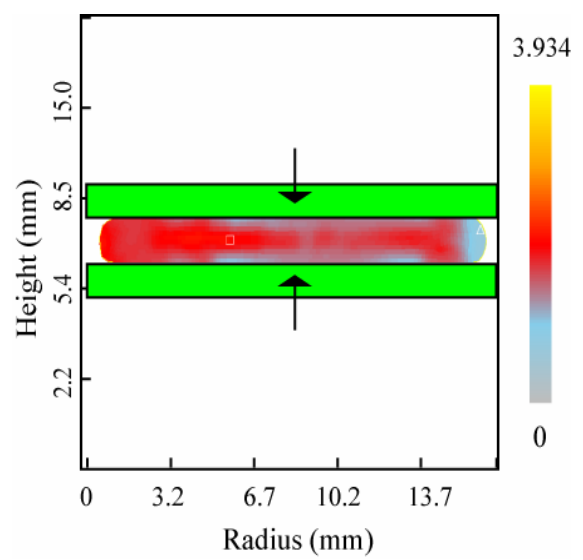

(d)

Figure 10: Strain evolution for hot forging of Ti-6Al-4V in a ring compression test geometry, using $m_{a}=1.0$ and $m_{l}=0.2$. (a) $20 \%$ reduction in thickness; (b) $40 \%$ reduction in thickness; (c) $60 \%$ reduction in thickness; (d) $76 \%$ reduction in thickness. 


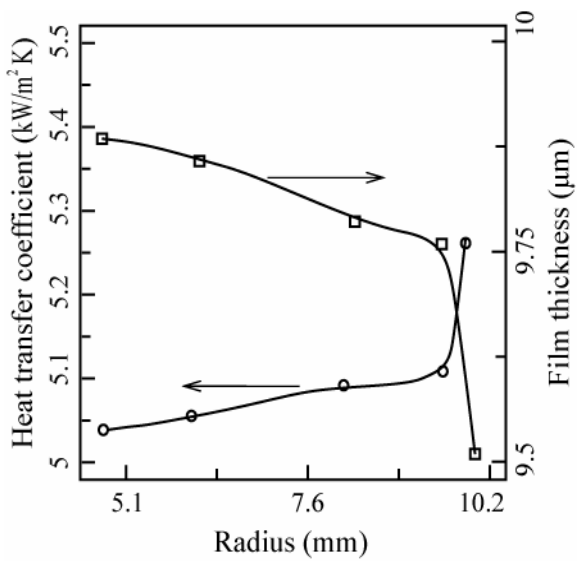

(a)

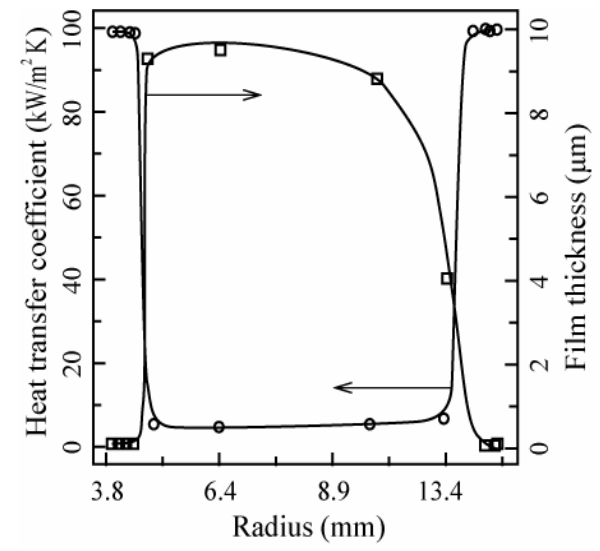

(c)

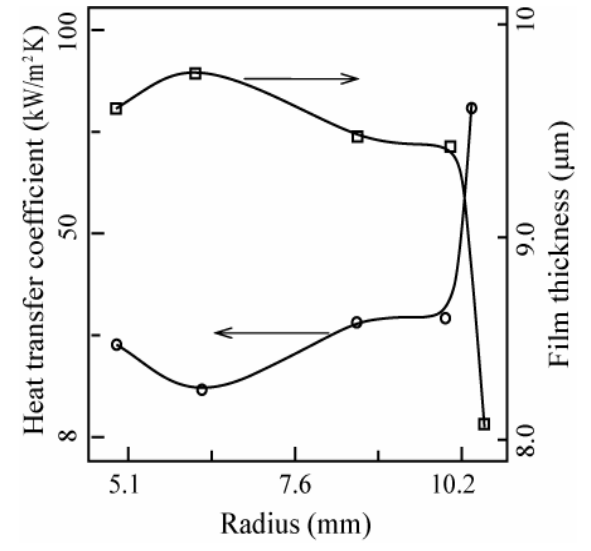

(b)

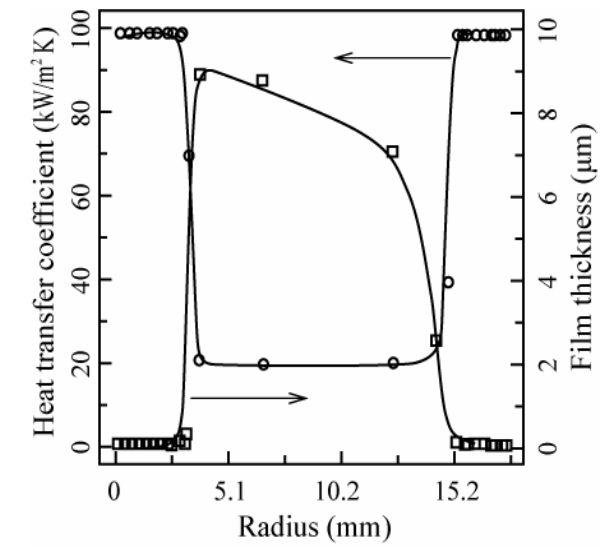

(d)

Figure 11: Film thickness and Heat Transfer coefficient evolution for hot forging of Ti-6Al-4V in a ring compression test geometry, using $m_{a}=1.0$ and $m_{l}=0.2$. (a) $20 \%$ reduction in thickness; (b) $40 \%$ reduction in thickness; (c) $60 \%$ reduction in thickness; (d) $76 \%$ reduction in thickness. 


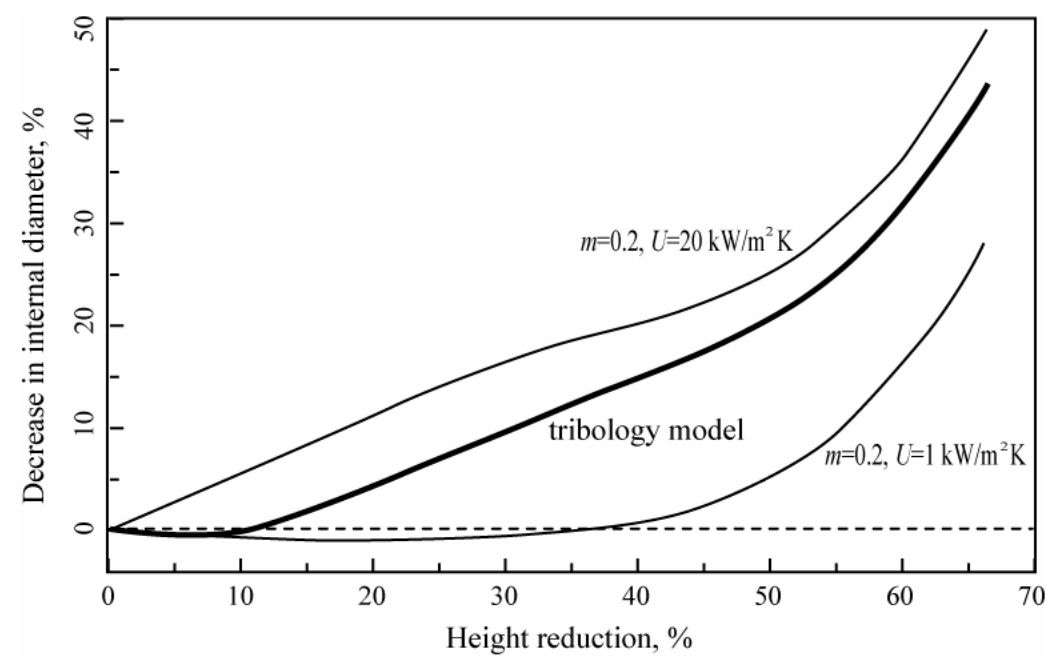

Figure 12: Internal diameter .vs. height reduction of hot RCTs from simulations using constant value approach and tribology model.

\section{References}

[1] Firat, M., "A finite element modeling and prediction of stamping formability of a dual-phase steel in cup drawing". Materials and Design 2012, 34, 32-39.

[2] Abdulhay, B., Bourouga, B., Desssain, C., Brun, G. and Wilsius, J., "Development of Estimation Procedure of Contact Heat Transfer Coefficient at the Part-Tool Interface in Hot Stamping Process", Heat Transfer Engineering 2011, Taylor and Francis Group.

[3] Bai, Q., Lin, J., Zhan, L., Dean, T.A., Balint, D.S. and Zhang, Z., "An Efficient Closed-form Method for Determining Interfacial Heat Transfer Coefficient in Metal Forming", International Journal of Machine Tools and Manufacture 2012, 56, 102-110.

[4] Gearing, B.P., Moon, H.S. and Anand, L. "A Plasticity Model for Interface Friction: Application to Sheet Metal Forming", International Journal of Plasticity 2001, 17, 237-271.

[5] Figueiredo, L., Ramalho, A., Oliveira, M.C. and Menezes, L.F., "Experimental Study of Friction in Sheet Metal Forming", Wear 2011, 217 (271), 1651-1657.

[6] Jackson, J.E., Gangjee, T. and Haque, I., "Lubricant Modeling and Its Effect on Simulation of Material Forming". J. Engineering Materials and Technology 1989, 111, 74-80.

[7] Kirkhorn, L., Bushlya, V., Andersson, M. and Stahl, E., "The Influence of Tool Steel Microstructure on Friction in Sheet Metal Forming". Wear 2013 ,302, 1268-1278.

[8] Kucharski, S., Starzynski, G. and Bartoszewicz, A., "Prediction of Surface Roughness in Metal Forming with Liquid Lubricant". Tribology International 2010, 43, 29-39.

[9] Hol, J., Alfaro, M.V., de Rooij, M.B. and Meinders, T., "Advanced Friction Modeling for Sheet Metal Forming", TATA Steel 2010. 
[10] Buchner,B., Buchner, M., Buchmayr, B., "Determination of the Real Contact Area for Numerical Simulation", Tribology International 2009, 42, 897-901.

[11] Haddag, B., Kagnaya, T., Nouari, M., Cutard, T., "A New Heat Transfer Analysis in Machining Based on Two Steps of 3D Finite Element Modelling and Experimental Validation", Heat Mass Transfer 2013, 49, 129-145.

[12] Schmid, S.R., Liu, J., and Wilson, W.R.D., "A New Tribology Model for the Simulation of Metal Forming Processes with the Finite Element Method," JSME/ASME Joint Conference, Honolulu, October 14-18, 2002.

[13] Liu, J., Wilson, W.R.D. and Schmid, S.R., "A Tribology Model for Finite Element Simulation of Hot Forging". J. of Materials Processing Technology 2004, 155-156, 1912-1917.

[14] Schmid, S.R. and Wilson, W.R.D., "Tribology in Manufacturing"; Modern Tribology Handbook, CRC Press, 2001; 1385-1412.

[15] Schmid, S.R., Sellés, M.A. and Pasang, T., "Tribology of Forging," in Wang, J. and Chung, Y.-W., eds.; Encyclopedia of Tribology, Springer, to appear 2013.

[16] Lin, Y.C. and Chen, X.M., "A critical review of experimental results and constitutive descriptions for metals and alloys in hot working (Review)". Materials and Design 2011, 32(4), 1733-1759.

[17] Ramezani, M. and Ripin,Z.M., "A friction model for dry contacts during metal-forming processes". International Journal of Advanced Manufacturing Technology 2010, 51, 93-102.

[18] Kondratiuk, J. and Kuhn, P., "Tribological Investigation on Friction and Wear Behaviour of Coatings for Hot Sheet Metal Forming", Wear 2011,270, 839-849.

[19] Wilson, W.R.D., "Friction and Lubrication in Bulk Metal Forming Processes". J. Appl. Metalworking 1979, 1-19.

[20] Wilson, W.R.D. and Marsault, N., "Partial Hydrodynamic Lubrication with Large Fractional Contact Areas". J. Tribology 1998, 120, 16-20.

[21] Wilson, W.R.D., Huang, X.B. and Hsu, T.C., "A Realistic Friction Model for Computer Simulation of Sheet Metal Forming Processes". J. Eng. Ind. 1995, 202-209.

[22] Christensen, H., "Stochastic Models for Hydrodynamic Lubrication of Rough Surfaces". Proc. IMechE 1970, 1013-1022.

[23] Schey, J.A., Tribology in Metalworking: Friction Lubrication and Wear. American Society for Metals, Metals Park 1984.

[24] Li, Y., Ying, L., Hu, P., Shi, D., Zhao, X. and Dai, M., "Coupled Numerical Simulation of Hot Stamping Process and Experimental Verification", American Institute of Physics 2013, 532, 471.

[25] Nshama, W. and Jeswiet, J., "Evaluation of Temperature and Heat Transfer Conditions at the Metal-Forming Interface", Annals of the CIRP 1995, 44, 201-203.

[26] Kannan, K., Pandheeradi, M., Vaze, S. and Schmid, S.R., "Modeling of Die-Workpiece Interface During Hot Forging". TMS Annual Meeting, Seattle, 2002.

[27] Incropera, F.P. and DeWitt, D.P., "Fundamentals of Heat Transfer", Wiley, 1996. 